Neurosurg Focus 14 (2):Article 8, 2003, Click here to return to Table of Contents

\title{
Bone grafting
}

\author{
Gregory J. Zipfel, M.D., Bernard H. Guiot, M.D., and Richard G. Fessler, M.D., Ph.D. \\ Department of Neurosurgery, University of Florida, Gainesville, Florida; Rocky Mountain \\ Neurosurgical Alliance, Aurora, Colorado; and Section of Neurosurgery, University of Chicago, \\ Chicago, Illinois
}

\begin{abstract}
In recent years our understanding of spinal fusion biology has improved. This includes the continued elucidation of the step-by-step cellular and molecular events involved in the prototypic bone induction cascade, as well as the identification and characterization of the various critical growth factors governing the process of bone formation and bone graft incorporation. Based on these fundamental principles, growth factor technology has been exploited in an attempt to improve rates of spinal fusion, and promising results have been realized in preclinical animal studies and initial clinical human studies. In this article the authors review the recent advances in the biology of bone fusion and provide a perspective on the future of spinal fusion, a future that will very likely include increased graft fusion rates and improved patient outcome as a result of the successful translation of fundamental bone fusion principles to the bedside.
\end{abstract}

KEY WORDS - bone graft - spinal fusion - bone morphogenetic protein • bone graft

Spinal fusion is a critical element in many spinal procedures. The incidence of nonunion ranges from 5 to $35 \%, 7,7,20,38$ and failed spinal fusions are a significant contributor to the morbidity associated with spinal surgery. In recent years our understanding of spinal fusion biology has improved, including the identification and characterization of various local and systemic growth factors. This argues well for improved spinal fusion rates in the future. Investigators of recent in vivo studies have shown the utility of this growth factor technology in multiple spinal fusion models, , $^{3,24,32,34}$ thus underscoring its bright future.

The aim of this article is to describe and illustrate the chronology of events occurring during the incorporation of bone grafts into a stable spinal fusion. First, the crucial topics of bone formation, bone graft physiology, and typical bone graft options are reviewed. Second, the step-bystep cellular and molecular events involved in the prototypic bone induction cascade are delineated. Third, a lumbar spinal fusion animal model is sequentially described, illustrating the bone induction cascade as it relates to the clinically relevant setting of spinal fusion. Finally, conclusions are drawn regarding the potential application of bone fusion principles, particularly the use of growth factors, in the clinical setting of spinal fusion.

Abbreviations used in this paper: $\mathrm{BMP}=$ bone morphogenetic protein; DBM = demineralized bone matrix; PDGF = plateletderived growth factor; PMNL = polymorphonuclear leukocyte; $\mathrm{TGF}=$ transforming growth factor; $\mathrm{TP}=$ transverse process.

\section{BONE FORMATION}

A firm grasp of the two different embryonic modes of osteogenesis is critical in understanding the biological principles of bone graft incorporation and spinal fusion. As illustrated by these two models, bone always develops by the replacement of preexisting connective tissue. Both modes of ossification are likely involved in spinal fusion, as will be described.

\section{Intramembranous Ossification}

Intramembranous ossification is bone formation produced by the direct differentiation of mesenchymal cells into osteoblasts. There is no cartilage intermediate. Certain flat bones of the skull and part of the mandible develop in this manner. Initially, the primitive mesenchymal cells condense into a rich, vascularized layer of connective tissue. The cells are embedded in an extracellular matrix composed of fine bundles of collagen fibrils and a gellike ground substance composed of proteoglycans. A trabeculated pattern of early bone matrix is then produced, concurrent with the differentiation of primitive mesenchymal cells into osteoblasts. Maturation of the bone matrix occurs through cellular synthesis and secretion of bone matrix components such as collagen, producing thickened and lengthened trabeculae. Shortly thereafter, the bone matrix becomes the site of calcium phosphate deposition in the form of hydroxyapatite crystals. The trabeculae continue to thicken during this mineralization process and ultimately sequester the osteoblasts in lacunae, forming 
osteocytes. In those areas destined to become compact bone, the trabeculae continue to thicken, eventually adopting a lamellar pattern of organization (not true lamellar bone, however). In those areas destined to become spongy bone, the trabeculae stop thickening and hemopoietic tissue develops. ${ }^{36}$

\section{Endochondral Ossification}

Endochondral ossification involves bone formation through a cartilage intermediate and is by far the most common mechanism of primary bone formation. The skull base, vertebral column, pelvis, and extremities are formed in this manner. Initially, a hyaline cartilage model develops, which subsequently undergoes a highly specific maturation process in preparation for its replacement by bone. This maturation initially involves the hypertrophy of chondrocytes, which impinges upon the intervening osseous matrix leading to matrix erosion. The cartilage matrix that remains then mineralizes, a crucial prerequisite step in the replacement of cartilage by bone. Eventually, the chondrocytes regress and die, and blood vessels, carrying primitive mesenchymal stem cells in their perivascular tissue, invade the calcified cartilage model. These stem cells populate the calcified cartilage and then differentiate into osteoblasts or hemopoietic tissue. The osteoblasts congregate on the calcified cartilage trabeculae and deposit bone matrix, a process that forms early trabeculae composed of a calcified cartilage core and outer osseous layer. The deposition of bone matrix continues, producing thickened and lengthened osseous trabeculae. The osseous matrix deposition either continues and forms cortical bone or halts and forms cancellous bone with intermixed hemopoietic tissue. ${ }^{36}$

\section{Bone Remodeling}

Bone remodeling is the replacement of primary bone (formed through intramembranous or endochondral ossification) by more precisely ordered lamellar or secondary bone, referred to as definitive haversian systems. At various sites in primary bone, osteoclast-produced bone resorption occurs and forms cavities. As this resorption progresses, long cylindrical cavities housing blood vessels and embryonic bone marrow develop. Eventually the resorption ceases and osteoblastic activity takes over. The osteoblasts produce concentric lamellae of bone in the walls of the cavity producing a typical osteon. These precisely organized lamellar osteons of secondary bone eventually replace all previously formed primary bone. This remodeling process continues throughout life, allowing an organism to conduct its usual skeletal and metabolic functions and allowing osseous adjustment to new mechanical conditions. $^{36}$

\section{BONE GRAFT PHYSIOLOGY}

The incorporation of a bone graft is defined as the "process of envelopment and interdigitation of the donor bone tissue with new bone deposited by the recipient."24 This process follows a typical multistep cascade that is briefly introduced here and defined in greater detail later. Initially, the bone graft produces a response leading to the accumulation of inflammatory cells, followed by the che- motaxis of host mesenchymal cells to the graft site. Thereafter, the primitive host cells differentiate into chondroblasts and osteoblasts, a process under the influence of various osteoinductive factors. The additional processes of bone graft revascularization and necrotic graft resorption occur concurrently. Finally, bone production from the osteoblasts onto the graft's three-dimensional framework occurs, followed by bone remodeling in response to mechanical stress. ${ }^{11}$

An ideal bone graft would provide all elements required during these phases of graft incorporation and lend structural support during the process. This ideal graft would possess the following: 1) an osteoconductive matrix that provides a nonviable three-dimensional framework amenable to the ingrowth of blood vessels and osteoprogenitor cells required for bone formation; 2) osteoinductive factors that recruit the recipient's mesenchymal cells through chemotaxis and then induce or modulate bone formation; 3 ) osteogenic cells that are graft cells with the potential to differentiate into osteoblasts; and 4) structural integrity that provides mechanical support to the spinal fusion. ${ }^{10}$ Many bone graft types are available to the spine surgeon today, and each possesses some of the aforementioned properties. The surgeon's choice of graft material depends greatly on which of the four elements are most crucial to the particular surgical application. For example, an interbody graft site would require structural integrity, whereas an intertransverse process graft site would place more emphasis on the osteogenic and osteoinductive properties of a graft.

\section{BONE GRAFT TYPES}

Various bone graft types including autografts, allografts, synthetic grafts, and others have been characterized and applied clinically. Of these, the most effective is that of the autologous cancellous variety, which possesses three of the four primary graft elements (Table 1). First, it has a collagen and hydroxyapatite osteoconductive framework that is superior to all other graft types. Second, its stroma is populated with various cells with osteogenic potential. Third, many osteoinductive factors including the fundamental BMPs are found within this graft. The autologous cortical bone graft has a more limited osteoconductive, -inductive, and -genic profile than cancellous grafts, but it has the attractive feature of providing initial stability to the spinal fusion. Finally, the autologous vascularized free cortical bone graft has similar attributes to that of the standard autologous cortical graft but is biomechanically superior during the initial 6 months postgrafting. This improved initial biomechanical profile has been exploited in orthopedic procedures requiring the bridging of significant osseous gaps but has had limited application in spinal procedures. Both autogenous cancellous and cortical bone grafts have the advantage of eliminating the risk of disease transfer during implantation and being histocompatible, but both have the disadvantages of donor site morbidity and limited bone stock availability. ${ }^{10}$

The allograft is another common bone graft alternative (Table 1). Fresh allografts provoke an intense immune response that precludes their use in spinal applications. Frozen allografts (grafts kept at $-60^{\circ} \mathrm{C}$ ) have identical biomechanical profiles to those of fresh grafts with a reduced 
Bone grafting

TABLE 1

Properties of bone graft alternatives*

\begin{tabular}{lcccccc}
\hline \hline \multicolumn{1}{c}{ Grafting Material } & $\begin{array}{c}\text { Osteo- } \\
\text { conduction }\end{array}$ & $\begin{array}{c}\text { Osteo- } \\
\text { induction }\end{array}$ & $\begin{array}{c}\text { Osteogen- } \\
\text { ic Cells }\end{array}$ & $\begin{array}{c}\text { Immuno- } \\
\text { genicity }\end{array}$ & $\begin{array}{c}\text { Donor-Site } \\
\text { Morbidity }\end{array}$ & $\begin{array}{c}\text { Immediate } \\
\text { Strength }\end{array}$ \\
\hline cancellous autologous graft & ++++ & ++ & +++ & - & + & - \\
cortical autologous graft & + & $+/-$ & $+/-$ & - & + & ++ \\
fresh allograft & + & $+/-$ & - & ++ & - & ++ \\
frozen allograft & + & $+/-$ & - & + & - & ++ \\
freeze-dried allograft & + & $+/-$ & - & $+/-$ & - & + \\
ceramics & + & $+/-$ & - & - & - & $+/-$ \\
DBM & + & - & - & - & - & - \\
bone marrow & - & $+/-$ & ++ & - & - & - \\
particulate ceramic w/ bone marrow & ++ & $+/-$ & ++ & - & - & - \\
\hline
\end{tabular}

* Data adapted with permission from Gazdag, et al. Abbreviations: $+=$ weak positive role; $++=$ more positive role; $+++=$ strong positive role; $++++=$ strongest positive role; $-=$ no role; $+/-=$ may play a role.

immunogenicity. Freeze-dried allografts (grafts that are lyophilized, placed in vacuum packs, and stored at room temperature) have a further reduction in antigenicity without sacrificing biomechanical properties and have become the most popular allograft alternative. All allografts maintain their osteoconductive and their limited osteoinductive capabilities following processing, but lose their osteogenicity. The transfer of disease (including HIV and hepatitis) is always a concern with allograft implantation; however, because of stringent donor-screening and tissuetesting regulations at every national tissue bank, this risk is extremely low. Elimination of donor site morbidity and improved availability are the attractive features of allografts compared with autografts. This, however, comes at the expense of a more limited osteoinductive profile and the loss of osteogenicity. ${ }^{10}$

Ceramics, DBM, bone marrow, and particulate ceramics with bone marrow are additional graft alternatives, each having its own characteristics (Table 1). ${ }^{10}$ These alternatives are not commonly used in spinal surgery at this time and will not be further addressed in this review.

\section{BONE GRAFT INCORPORATION}

In the mid-1960s Urist ${ }^{41}$ first reported the induction of bone formation at an extraskeletal site by the implantation of DBM. This sentinel discovery ignited a fury of research activity that has led to a vastly superior understanding of the step-by-step process of bone formation, including the role of osteoinductive factors. The cellular and biochemical cascade involved in the DBM bone induction model have been well documented and many parallels to common clinical settings of bone induction (including fracture healing and bone graft incorporation) have been drawn. ${ }^{13,17,31}$ Because there are multiple spinal procedures potentially involving any of the aforementioned graft options, the discussion herein focuses on the DBM prototypic bone induction cascade. Interspersed throughout this discussion are relevant points regarding the clinical settings of fracture healing and bone graft incorporation.

The bone induction cascade has often been segregated into prominent phases. The initial phase involves mesenchymal cell chemotaxis and proliferation. This is a growth factor-stimulated accumulation of primitive mesenchymal cells and is critical to the ensuing phases of bone induction. The second phase involves the differentiation of these primitive cells into chondroblasts and chondrocytes with the subsequent production of cartilaginous matrix. This second phase concludes when blood vessels invade the newly formed cartilage, carrying primitive mesenchymal cells along to populate the cartilage with osteogenic precursors. The third and final phase is the mesenchymal cell differentiation into osteoblasts and osteocytes, followed by bone and bone marrow production. ${ }^{29}$

The DBM that induced this cascade is a repository of various osteoinductive factors such as BMPs, TGF $\beta$, and insulin-like growth factors. These factors have been shown to induce osteoblast proliferation and differentiation in vitro and to stimulate bone formation when administered in vivo. ${ }^{21}$ Some of these factors have been implicated not only in the initiation but also in the promotion, maintenance, and termination of bone formation. ${ }^{9}$ Finally, a role in cellular chemotaxis and in the production of early inductive factors has been demonstrated for two BMP subtypes, suggesting that these factors are also involved in the very early stages of the bone induction cascade. ${ }^{9}$ The overall role of these growth factors thus appears to include all phases of bone induction, from initiation through termination of bone formation.

\section{Phase I: Mesenchymal Cell Chemotaxis and Proliferation (Days 0-4)}

During the first minute following DBM implantation, a blood clot forms producing a fibrin network. Aggregating platelets release multiple growth factors such as TGF $\beta$ and PDGF, and there is plasma fibronectin binding to the implanted matrix. The TGF $\beta$ has various effects that promote bone induction, including stimulating the production of other bone inducing growth factors, promoting the production of various bone and cartilage components, ${ }^{21}$ and causing osteoblast chemotaxis ${ }^{27}$ and proliferation. ${ }^{23}$ The PDGF is a prominent mitogen for connective tissue cells ${ }^{31}$ and also may play a role in the regulation of cell growth and differentiation. ${ }^{26}$ Finally, fibronectin peptides have potent chemotactic and perhaps mitogenic effects as well. ${ }^{29}$ Therefore, within the first minute of implantation, the bone induction cascade has been initiated through the release of various chemotactic and mitogenic factors (Table 2). 
TABLE 2

Multistep bone induction cascade*

\begin{tabular}{|c|c|c|}
\hline $\begin{array}{l}\text { Time After } \\
\text { Implantation }\end{array}$ & Cellular Events & Molecular Processes \\
\hline $1 \mathrm{~min}$ & blood clot formation, platelet aggregation & $\begin{array}{l}\text { fibrin network formation, platelet release of TGF } \beta \text { \& PDGF, plasma fibro- } \\
\text { nectin binding to implanted matrix }\end{array}$ \\
\hline $1 \mathrm{hr}$ & PMNL arrival by chemotaxis & release of collagenase, elastase, \& other enzymes; release of collagenous peptides \\
\hline $3-18 \mathrm{hrs}$ & accumulation of PMNLs & continued proteolysis $\mathrm{w} /$ release of fibroblast chemotactic factors \\
\hline Day 1 & $\begin{array}{l}\text { mesenchymal cell chemotaxis, cell attachment } \\
\text { to the implanted matrix }\end{array}$ & release of fibronectin peptides \\
\hline Day 2 & $\begin{array}{l}\text { continued mesenchymal cell chemotaxis, matrix- } \\
\text { to-cell signal transduction }\end{array}$ & initiation of nucleic acid \& protein synthesis, release of further growth factors \\
\hline Day 3 & mesenchymal cell proliferation & ${ }^{3} \mathrm{H}$-thymidine incorporation into DNA,Type III collagen synthesis \\
\hline Day 5 & chondroblast differentiation & increased ${ }^{35} \mathrm{SO}_{4}$ incorporation proteoglycans \\
\hline Day 7 & $\begin{array}{l}\text { chondrocyte differentiation, synthesis \& se- } \\
\text { cretion of matrix }\end{array}$ & Type II collagen synthesis, cartilage-specific proteoglycan synthesis \\
\hline Day 9 & $\begin{array}{l}\text { chondrocyte hypertrophy, cartilage matrix calci- } \\
\text { fication, vascular invasion of calcified matrix }\end{array}$ & $\begin{array}{l}\text { increased }{ }^{45} \mathrm{Ca} \text { incorporation, increased alkaline phosphatase activity, Type IV } \\
\text { collagen synthesis, detection of laminin \& factor VIII }\end{array}$ \\
\hline Days $10-12$ & $\begin{array}{l}\text { osteoblast differentiation, bone formation, bone } \\
\text { mineralization }\end{array}$ & $\begin{array}{l}\text { Type I collagen synthesis, bone-specific proteoglycan synthesis, peak in }{ }^{45} \mathrm{Ca} \\
\text { incorporation, peak in alkaline phosphatase activity }\end{array}$ \\
\hline Days $12-18$ & $\begin{array}{l}\text { increased osteoclastic activity, bone remodeling } \\
\& \text { dissolution of implanted matrix }\end{array}$ & increased lysosomal enzyme activity, release of collagenases \& proteases \\
\hline Day 21 & bone marrow differentiation & increased ${ }^{59} \mathrm{Fe}$ incorporation into heme \\
\hline
\end{tabular}

* Adapted with permission from Reddi, et al.

During the next 18 hours, there is a chemotactic-driven arrival and accumulation of inflammatory cells such as PMNLs. There is also the release of collagenase and elastase, producing well-known chemotactic factors such as collagenous and fibronectin peptides. The chemotactic stimulus initiated in the 1st minute following implantation has thus undergone a significant amplification during the ensuing hours postimplantation. ${ }^{29}$

After blood clot formation and inflammation, there is a 2-day period of fibroblast-like mesenchymal cell chemotaxis, a process largely driven by the aforementioned proteolytic peptides and growth factors. The mesenchymal cells arrive and subsequently attach to the implanted matrix. This interaction is mediated by fibronectin and other cell-adhesive proteins. As the chemotactic process nears completion, two activities are noted: 1) protein and nucleic acid synthesis is initiated to prepare for the ensuing cellular proliferation; and 2) further amplification of the bone induction cascade occurs through the release of additional growth factors. ${ }^{29}$

The fibroblast-like mesenchymal cells then proliferate during the 3rd and 4th days postimplantation. Again, this proliferation is largely driven by the mitogenic effects of the previously released growth factors. There is an associated incorporation of ${ }^{3} \mathrm{H}$-thymidine into cellular DNA (a molecular process typically seen in times of cell mitogenesis) and an associated synthesis of Type III collagen (a fibrillar collagen characteristic of mesenchyme ${ }^{31}$ ). The tight interaction between the implanted matrix and mesenchymal cells continues to develop, and a transduced signal between the matrix and cell surface appears to initiate mesenchymal cell differentiation. ${ }^{29}$ This step marks the transition to the second phase of bone induction, mesenchymal cell differentiation into cartilage.

Before moving to the cellular differentiation description, a correlation between the DBM bone induction cascade and common clinical settings is warranted. As previ- ously suggested, the DBM bone induction cascade has many parallels with settings such as fracture healing and bone graft incorporation. With regard to fracture healing, many authors have noted the initial development of a hematoma, followed by the release of various chemoattractants, angiogenic factors, and growth factors from the aggregating platelets and local damaged tissue. A prominent influx of cells including granulocytes and primitive mesenchymal cells soon follows. . $^{12,15,30,35,37}$ Nearly identical descriptions of these early cellular steps have been noted in the literature concerning bone grafts as well., $3,5,14$ Burchardt and Enneking ${ }^{5}$ compared cancellous and cortical bone graft incorporation and noted an identical early inflammatory process followed by fibroblast-like cell accumulation in both. It thus appears that this initial inflammatory phase and subsequent mesenchymal cell accumulation is a universal initiating step in the bone induction cascade.

\section{Phase II: Mesenchymal Cell Differentiation Into Cartilage (Days 5-9)}

Five days following bone matrix implantation, the first cells and molecular markers indicative of cartilage differentiation are seen. Histologically, chondroblasts are noted on Day 5, marking the beginning of the differentiation phase. The incorporation of ${ }^{35} \mathrm{SO}_{4}$ into cartilage-specific proteoglycans and the immunofluorescent localization of Type II collagen (the major fibrillar collagen of cartilage ${ }^{31}$ ) coincide with this histology. By Day 7, chondrocytes are evident and there is further synthesis and secretion of cartilaginous matrix. By Day 9, the typical pattern of cartilage maturation described in endochondral bone formation is observed. There is chondrocyte hypertrophy, erosion of the intervening cartilaginous matrix, and mineralization of the remaining matrix trabeculae. The appropriate molecular markers of increased ${ }^{45} \mathrm{Ca}$ incorporation and increased alkaline phosphatase activity are concomi- 
tantly seen. Finally, vascular invasion of the newly formed cartilage occurs. This is seen histologically and is also accompanied by the detection of Type-IV collagen, laminin, and factor VIII (all common blood vessel components). ${ }^{29}$ This vascular invasion marks the transition from the cartilage differentiation phase to the final phase of bone induction, osteogenic precursor differentiation into bone (Table 2).

It has been generally accepted that endochondral bone formation with the production of a cartilaginous intermediary is at least a component of the natural healing of fractures. In a rat fracture model, one group of investigators $^{13,17}$ noted endochondral bone formation and demonstrated numerous parallels with the DBM bone induction cascade. These parallels included the condensation of mesenchymal cells on the fracture ends by Day 3, mesenchymal cell differentiation into cartilage by Day 5 , and vascular invasion of the cartilage intermediary by Days 9 through 11. Bone differentiation and bone formation commenced thereafter.

On the other hand, the degree to which endochondral compared with membranous bone formation contributed to fracture healing has produced some debate. McKibbin ${ }^{25}$ described a two-callus response in a natural fracture healing experimental model. The primary callus involved the direct production of bone through membranous ossification, whereas the inductive callus involved indirect bone production through endochondral bone formation. Two separate sources of osteoprogenitor cells leading to this two-callus response was proposed. Confirmatory evidence of these observations, however, are lacking.

The contribution of endochondral bone formation in bone graft spinal fusion procedures has produced even more debate than that seen in the fracture healing literature. Some authors have suggested that it plays a significant role in the healing of spinal fusions with bone grafts, $3,14,18,37,39$ whereas others have not demonstrated this endochondral component. ${ }^{1,16}$ Part of this confusion stems from the use of multiple spinal fusion models, many of which are less than representative of the true clinical surgical procedures. Boden, et al., ${ }^{3}$ systematically described an autograft-intertransverse process lumbar fusion rabbit model, characteristics of which were very reminiscent of the surgical procedure in use today. They noted involvement of both membranous and endochondral bone formation, with the endochondral process occurring centrally within the bone mass. The result of this well-designed study lend credence to the earlier reports noting endochondral bone formation in spinal fusions.

When comparing the bone induction cascade of DBM, fracture healing, and bone grafting in spinal fusions, a general theme has again emerged. In each of these settings, endochondral bone formation was demonstrated. It appears that cartilage has unique qualities that lend themselves well to the clinical settings of fracture healing and bone grafting. One of the first goals of bone healing in any setting is the restoration of stability, and fibrocartilage has unique swelling properties that give it considerable stabilizing capabilities. The cartilage-specific proteoglycans have long glycosaminoglycan chains with negatively charged chondroitin sulfate and keratan sulfate. These result in large aqueous domains that provide mechanical sta- bility to a developing callus by increasing its intrinsic pressure. ${ }^{31}$ It therefore appears that this cartilage is not only an intermediary in the process of bone formation but also provides an important structural function to the ongoing fusion mass.

\section{Phase III: Mesenchymal Cell Differentiation Into Bone (Days 10-21)}

Ten days after DBM implantation, the first osteoblasts are noted, and new bone formation is observed on the surface of the remaining calcified cartilage matrix (Table 2 ). These cellular events are associated with molecular processes consistent with bone formation, including Type I collagen synthesis (the major fibrillar collagen of bone $^{31}$ ), bone-specific proteoglycan synthesis, and a peak in ${ }^{45} \mathrm{Ca}$ incorporation and alkaline phosphatase activity. By Days 12 through 18, multinucleated osteoclasts are observed histologically and begin the process of bone remodeling. The osteoclasts and osteoblasts work in tandem to replace gradually early bone and remaining calcified cartilage with pure bone ossicles. The expected molecular processes of increased lysosomal enzyme activity and release of collagenases and proteases is concurrently seen. By Day 21, bone marrow differentiation occurs and the appearance of erythrocytic, granulocytic, and megakaryocytic lineages is noted. An associated increase of ${ }^{59} \mathrm{Fe}$ incorporation into heme accompanies their appearance. ${ }^{29}$

As has been noted, this DBM bone induction cascade is a growth factor-driven, highly structured step-by-step process with multiple points of amplification and regulation. This cascade has a strong correlation chronologically and temporally with that seen in common animal models of natural fracture healing. ${ }^{15}$ Bone graft incorporation, however, is considerably more complex with two processes including necrotic graft resorption and graft revascularization occurring concurrently with the bone induction cascade. ${ }^{5}$ In this setting, the chronology of the bone induction cascade is quite similar to aforementioned cascade, but the temporal profile can vary greatly depending on the graft type used.

Burchardt and Enneking ${ }^{5}$ have elegantly demonstrated such a temporal difference when they compared the graft incorporation characteristics of cancellous and cortical bone. They first described the universal initiating steps of bone induction in each graft type. This included the formation of a blood clot, inflammatory cell accumulation, and fibroblast chemotaxis (Week 1). An identical 2nd week of osteoclast resorptive activity and osteocyte autolysis is seen in each graft type as well. It is at this juncture, however, that differences occurred between the cancellous and cortical grafts. Cancellous bone typically revascularized within 2 weeks of implantation, whereas cortical grafts required 2 months for complete revascularization. Cancellous bone is initially strengthened by new bone formation and progressively gains more strength as the bone induction cascade proceeds. Cortical bone, on other hand, loses much of its initial structural integrity during the first 6 months because of the aforementioned osteoclastic resorptive process. As bone formation continues, this strength is gradually regained during the second 6-month period. Finally, cancellous grafts typically become completely remodeled (the entire graft is resorbed and re- 
placed with new bone), whereas cortical grafts are often incompletely remodeled for many months (various pockets of necrotic graft remain). These observations thus illustrate a general temporal lag in the typical bone graft incorporation cascade when a more compact, cortical graft is used.

\section{A CLINICALLY RELEVANT LUMBAR FUSION ANIMAL MODEL}

As mentioned previously, Boden, et al., ${ }^{3}$ have elegantly characterized a clinically relevant rabbit model of lumbar spinal fusion. Each rabbit underwent posterolateral intertransverse process fusion in which autogenous iliac crest corticocancellous bone was used. A sequential histological analysis of this model revealed a continuum of three bone graft incorporation phases.

First, there was an inflammatory phase (Week 1-3) reminiscent of the initial observed events seen in the DBM bone induction cascade. The decortication and disruption of the local blood supply resulted in an initial hematoma at the graft site, and an accumulation of inflammatory cells such as PMNLs soon followed. Progressively thereafter, fibroblast-like mesenchymal cells appeared and

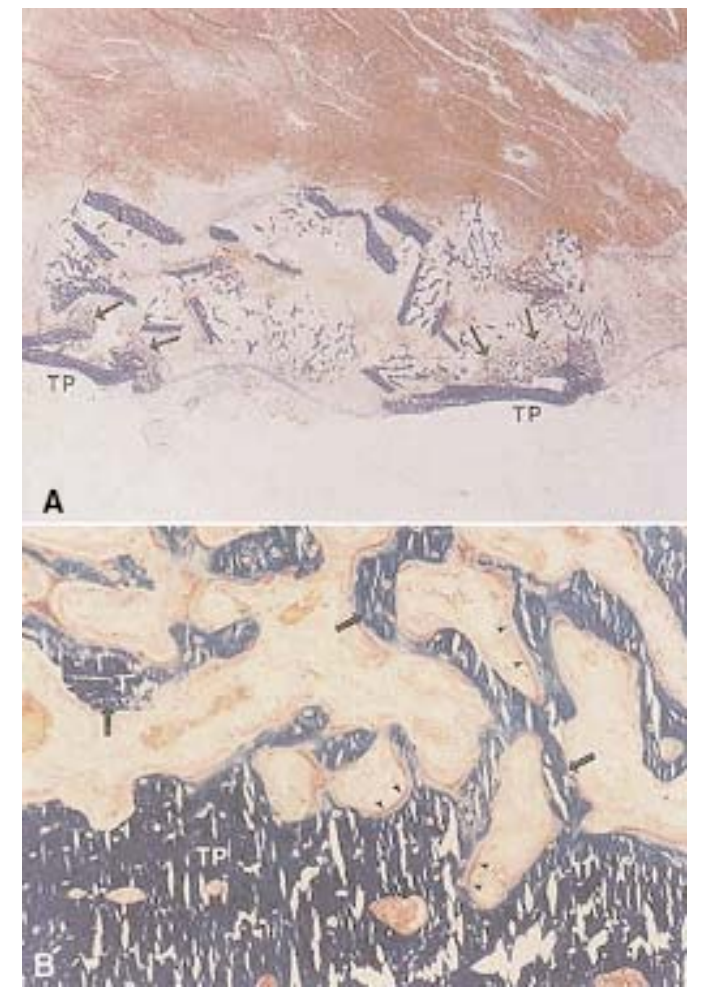

Fig. 1. Photomicrographs showing the early phase of bone graft incorporation in a rabbit model of lumbar spinal fusion (adapted from Boden, et al., 1995, with permission). Sagittal sections of a rabbit's intertransverse processes fusion mass 2 weeks after arthrodesis with autogenous iliac crest corticocancellous bone. A: Low-power photomicrograph showing early bone formation (arrows) along the TPs. B: Higher-power photomicrograph showing trabecular bone formation (arrows) with osteoid seams (arrowheads) near the TP. Goldner Trichrome. transformed the clot into a fibrovascular stroma. The beginning of membranous bone formation was seen at the decorticated surface of the transverse processes (TP) and early evidence of endochondral bone formation was seen in between the bone graft fragments (Fig. 1). These observations provide strong evidence that indeed the first phase of the DBM bone induction cascade occurs in this animal model but at a delayed pace. ${ }^{3}$

In the middle or reparative phase (Weeks 4 and 5) a continuation of the membranous and endochondral bone formation initially observed in the previous stage results in a progressive solidification of the spinal fusion. This bone formed concurrently with other processes typically seen following bone graft implantation, including the resorption of necrotic graft tissue and the revascularization of the implanted graft. The membranous bone formation was evident at the TPs and extended toward the center of the fusion mass, whereas the endochondral bone formation occurred centrally at the interface between the upper and lower halves of the fusion mass (Fig. 2). This central endochondral process was attributed to the tolerance of cartilage to the low oxygen saturation observed centrally or to the motion present between the upper and lower portions of the fusion mass. ${ }^{3}$ Overall, this bone for-

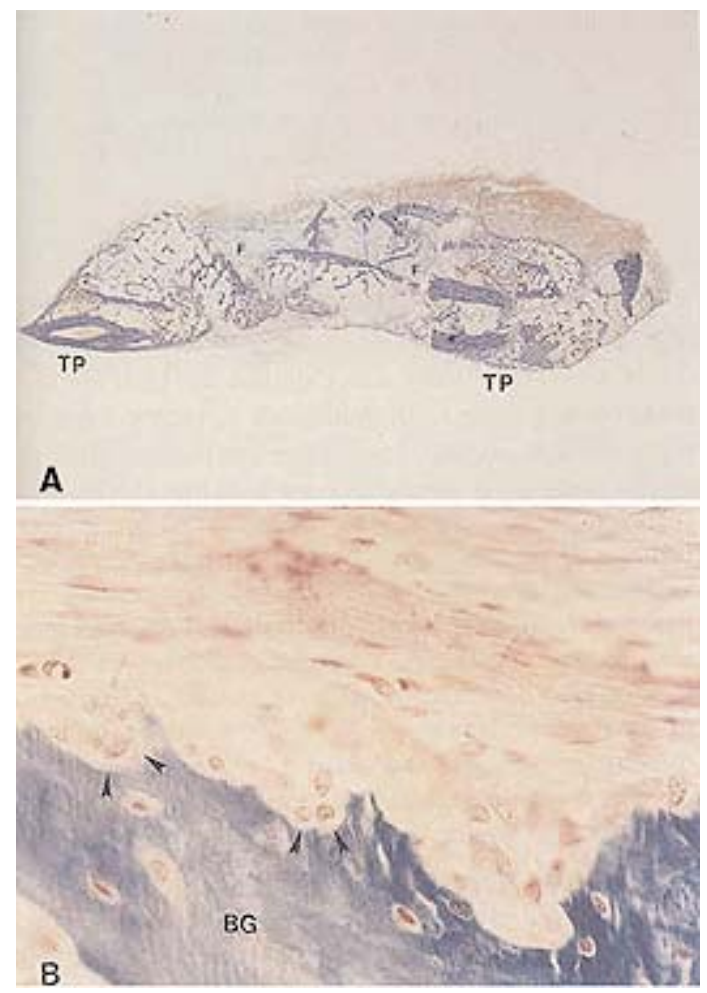

Fig. 2. Photomicrographs showing the middle phase of bone graft incorporation in a rabbit model of lumbar spinal fusion (adapted from Boden, et al., 1995, with permission). Sagittal sections of a rabbit's intertransverse processes fusion mass 5 weeks after arthrodesis with autogenous iliac crest corticocancellous bone. A: Low-power photomicrograph showing new bone formation near the TP. The graft is interconnected centrally by fibrocartilaginous tissue (F). B) Higher-power photomicrograph showing resorption (arrowheads) of the bone graft. Goldner Trichrome. 
mation exhibited parallels to the DBM bone induction cascade but occurred in a delayed fashion.

In the late or remodeling phase (Week 6-10) a dramatic remodeling of the early bone fusion mass was demonstrated. The fusion mass initially had a thin cortical rim surrounding a center composed of secondary spongiosa and bone marrow (Fig. 3). As the remodeling process progressed, the cortical rim thickened and newly formed trabeculae extended toward the center of the fusion. ${ }^{3}$ This remodeling was slower but reminiscent of that seen in the DBM bone induction cascade and is a critical element of the biomechanical development of a fusion mass.

This sequential histological analysis of a rabbit lumbar fusion model suggested that spinal fusions involving bone grafts is a complex, but highly regulated process. The DBM prototypic bone induction cascade for endochondral bone formation was used in conjunction with other processes such as necrotic graft resorption, graft revascularization, and membranous bone formation. This process is assuredly directed by the inductive and modulatory capabilities of the various growth factors present within the implanted bone graft. The hypothesis that augmentation of a spinal fusion procedure with osteoinductive factors thus appears sound.

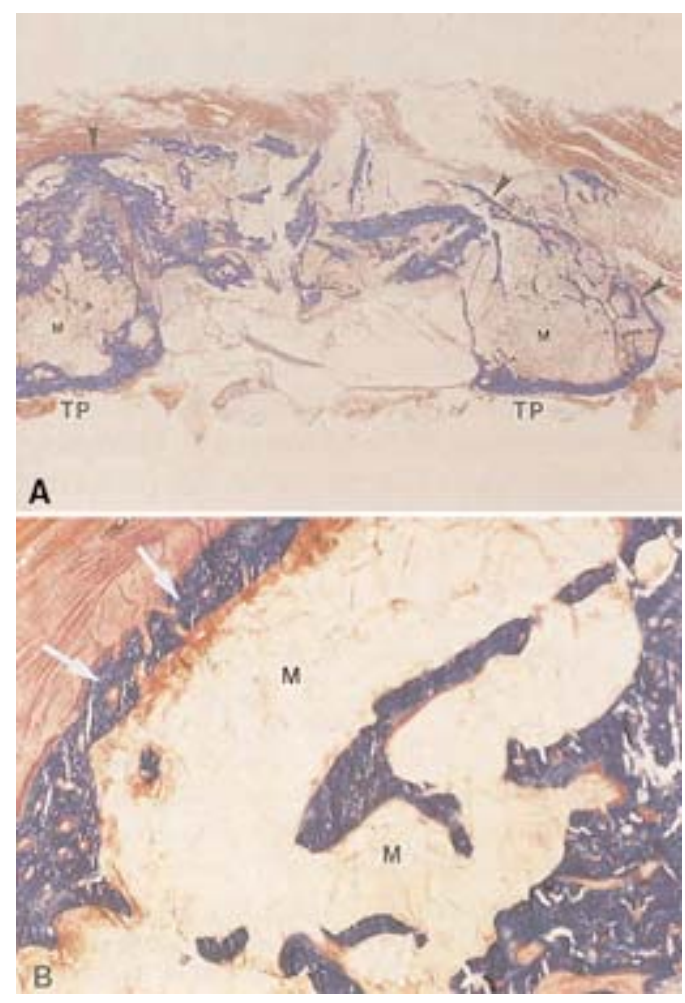

Fig. 3. Photomicrographs showing late phase of bone graft incorporation in a rabbit model of lumbar spinal fusion (adapted from Boden, et al., 1995, with permission). Sagittal sections of a rabbit's intertransverse processes fusion mass 10 weeks after arthrodesis with autogenous iliac crest corticocancellous bone. A: Low-power photomicrograph showing that advanced remodeling of the fusion mass near the TP has occurred; a cortical rim (arrowheads) has developed, and marrow formation (M) has begun. B: Higher-power photomicrograph showing the cortical rim (arrows) and marrow formation (M). Goldner Trichrome.

\section{CONCLUSIONS AND FUTURE DIRECTIONS}

During the past two decades since Urist's sentinel discovery of bone induction, ${ }^{41}$ our understanding of bone graft biology has evolved. The description of the cellular and molecular processes involved in the bone induction cascade and the identification and characterization of various growth factors have set the stage for an exciting future in spinal surgery. Based on these fundamental concepts, various investigators ${ }^{3,24,28,29}$ have successfully used growth factor technology in multiple animal models of spinal fusion. Of those factors thus far investigated, BMPs have shown the most promise to date. In preclinical studies, BMPs have proven efficacious in both posterolateral and anterior interbody spinal fusion animal models, with the authors of several studies demonstrating superiority of BMP-augmented implants over autograft alone. , $, 6,22,32-34^{-1}$ Moreover, findings derived from initial clinical trials involving recombinant BMP technology for spinal fusion in humans appear promising., ${ }^{419}$ Although many questions remain (for example, growth factor dosing, optimizing site-specific delivery vehicles, and cost analysis), these techniques, firmly based on fundamental bone biology, will very likely lead to improved graft fusion rates and improved patient outcome in the near future.

\section{References}

1. Albee FH: An experimental study of bone growth and the spinal bone transplant. JAMA 60:1044-1049, 1913

2. Boden SD, Moskovitz PA, Morone MA, et al: Video-assisted lateral intertransverse process arthrodesis. Validation of a new minimally invasive lumbar spinal fusion technique in the rabbit and nonhuman primate (rhesus) models. Spine 21:2689-2697, 1996

3. Boden SD, Schimandle JH, Hutton WC, et al: 1995 Volvo Award in basic sciences. The use of an osteoinductive growth factor for lumbar spinal fusion. Part I: Biology of spinal fusion. Spine 20:2626-2632, 1995

4. Boden SD, Zdeblick TA, Sandhu HS, et al: The use of rhBMP2 in interbody fusion cages. Definitive evidence of osteoinduction in humans: a preliminary report. Spine 25:376-381, 2000

5. Burchardt H, Enneking WF: Transplantation of bone. Surg Clin North Am 58:403-427, 1978

6. Cook SD, Dalton JE, Prewett AB, et al: In vivo evaluation of demineralized bone matrix as a bone graft substitute for posterior spinal fusion. Spine 20:877-886, 1995

7. DePalma AF, Rothman RH: The nature of pseudarthrosis. Clin Orthop 59:113-118, 1968

8. Eie N, Solgaard T, Kleppe H: The knee-elbow position in lumbar disc surgery: a review of complications. Spine 8:897-900, 1983

9. Elima K: Osteoinductive proteins. Ann Med 25:395-402, 1993

10. Gazdag, AR, Lane JM, Glaser D, et al: Alternatives to autogenous bone graft: efficacy and indications. J Am Acad Orthop Surg 3:1-8, 1995

11. Goldberg VM, Stevenson S: The biology of bone grafts. Semin Arthroplasty 4:58-63, 1993

12. Grotendorst GR, Martin GR: Cell movements in wound-healing and fibrosis. Rheumatology 10:385-403, 1986

13. Henricson A, Hulth A, Johnell O: The cartilaginous fracture callus in rats. Acta Orthop Scand 58:244-248, 1987

14. Holmes R, Mooney V, Bucholz R, et al: A coralline hydroxyapatite bone graft substitute. Preliminary report. Clin Orthop 188:252-262, 1984

15. Hulth A: Current concepts of fracture healing. Clin Orthop 249:265-284, 1989 


\section{G. J. Zipfel, B. H. Guiot, and R. G. Fessler}

16. Hurley LA, Stinchfield FE, Bassett AL, et al: The role of soft tissues in osteogenesis: An experimental study of canine spine fusions. J Bone Joint Surg Am 41:1243-1254, 1959

17. Johnell O, Hulth A, Heinegard D, et al: Immunolocalization of bone and cartilage specific proteins and proteoglycans in experimental fracture healing. Calcif Tissue Int 42 (Suppl):A32, 1988 (Abstract)

18. Kahanovitz N, Arnoczky SP, Hulse D, et al: The effect of postoperative electromagnetic pulsing on canine posterior spinal fusions. Spine 9:273-279, 1984

19. Kleeman TJ, Ahn UM, Talbot-Kleeman A: Laparoscopic anterior lumbar interbody fusion with rhBMP-2: a prospective study of clinical and radiographic outcomes. Spine 26: 2751-2756, 2001

20. Lehmann TR, LaRocca HS: Repeat lumbar surgery. A review of patients with failure from previous lumbar surgery treated by spinal canal exploration and lumbar spinal fusion. Spine 6: 615-619, 1981

21. Linkhart TA, Mohan S, Baylink DJ: Growth factors for bone growth and repair: IGF, TGF-beta, and BMP. Bone 19 (Suppl 1):1-12, 1996

22. Lovell TP, Dawson EG, Nilsson OS, et al: Augmentation of spinal fusion with bone morphogenetic protein in dogs. Clin Orthop 243:266-274, 1989

23. Massague J: The transforming growth factor-beta family. Annu Rev Cell Biol 6:597-641, 1990

24. Morone MA, Boden SD, Hair G, et al: The Marshall R. Urist Young Investigator Award. Gene expression during autograft lumbar spine fusion and the effect of bone morphogenetic protein 2. Clin Orthop 351:252-265, 1998

25. McKibbin B: The biology of fracture healing in long bones. $\mathbf{J}$ Bone Joint Surg Br 60:150-162, 1978

26. Muller R, Bravo R, Burckhardt J, et al: Induction of c-fos gene and protein by growth factors precedes activation of c-myc. Nature 312:716-720, 1984

27. Oikarinen J: Experimental spinal fusion with decalcified bone matrix and deep-frozen allogeneic bone in rabbits. Clin Orthop 162:210-218, 1982

28. Pfeilschifter J, Chenu C, Bird A, et al: Interleukin-1 and tumor necrosis factor stimulate the formation of human osteoclast-like cells in vitro. J Bone Miner Res 4:113-118, 1989

29. Prolo DJ, Rodrigo JJ: Contemporary bone graft physiology and surgery. Clin Orthop 200:322-342, 1985

30. Reddi AH, Wientroub S, Muthukumaran N: Biologic principles of bone induction. Orthop Clin North Am 18:207-212, 1987

31. Ross R, Raines EW, Bowen-Pope DF: The biology of plateletderived growth factor. Cell 46:155-169, 1986

32. Sandberg MM, Aro HT, Vuorio EI: Gene expression during bone repair. Clin Orthop 289:292-312, 1993

33. Sandhu HS, Kanim LE, Kabo JM, et al: Effective doses of recombinant human bone morphogenetic protein-2 in experimental spinal fusion. Spine 21:2115-2122, 1996

34. Schimandle JH, Boden SD, Hutton WC: Experimental spinal fusion with recombinant human bone morphogenetic protein-2. Spine 20:1326-1337, 1995

35. Seeley RR, Stephens TD, Tate P: Anatomy and Physiology. St. Louis: Mosby, 1989, pp 154-175

36. Sheehan JP, Kallmes DF, Sheehan JM, et al: Molecular methods of enhancing lumbar spine fusion. Neurosurgery 39: 548-554, 1996

37. Sporn MB, Roberts AB, Wakefield LM, et al: Some recent advances in the chemistry and biology of transforming growth factor-beta. J Cell Biol 105:1039-1045, 1987

38. Sprugel KH, McPherson JM, Clowes AW, et al: Effects of growth factors in vivo. I. Cell ingrowth into porous subcutaneous chambers. Am J Pathol 129:601-613, 1987

39. Steinmann JC, Herkowitz HN: Pseudarthrosis of the spine. Clin Orthop 284:80-90, 1992

40. Thomas I, Kirkaldy-Willis WH, Singh S, et al: Experimental spinal fusion in guinea pigs and dogs: The effect of immobilization. Clin Orthop 112:363-375, 1975

41. Urist MR: Bone: formation by autoinduction. Science 150: 893-899, 1965

Manuscript received December 9, 2002.

Accepted in final form January 10, 2003.

Address reprint requests to: Richard G. Fessler, M.D., Ph.D., Professor of Surgery; Chief, Section of Neurosurgery, University of Chicago, 5841 S. Maryland Avenue MC 3026, Chicago, Illinois 60637. 